\title{
Pengetahuan Kader Posbindu terhadap Penyakit Diabetes Melitus
}

\author{
${ }^{1}$ Yesika Sengkey \\ ${ }^{2}$ Henry M. F. Palandeng \\ ${ }^{2}$ Tyrsa C. N. Monintja
}

\author{
${ }^{1}$ Kandidat Skripsi Fakultas Kedokteran Universitas Sam Ratulangi Manado \\ ${ }^{2}$ Bagian IKKOM Fakultas Kedokteran Universitas Sam Ratulangi Manado \\ Email: ysengkey@yahoo.com
}

\begin{abstract}
Riskesdas (Basic Health Research) 2013 showed that the prevalence of diabetes mellitus (DM) in Indonesia was $6.9 \%$ for those above 15 years and in North Sulawesi in 2013 was $2.4 \%$. Posbindu is a public health service post for elderly in a certain region driven by the community. At Posbindu, the elderly can get integrated health services as well as activities involving health promotion and well-being arranged by the community and social organization. Posbindu cadres are trained community workers set up in a communication forum technology transfered and public health guidance services by and for the people that has a strategic value in developing human resources as early as possible. Therefore, it is necessary to improve the knowledge of Posbindu cadres about DM and related diseases. This study was aimed to obtain the cadres' knowledge about DM. This was a qualitative study using informants. The results showed that the informants' knowledge about DM was very good, however, there were several things that should be improved. Conclusion: The informants had already known the important things that must be considered in the community, especially related to DM.
\end{abstract}

Keywords: knowledge, Posbindu cadre, diabetes mellitus.

\begin{abstract}
Abstrak: Riset Kesehatan Dasar (2013) menunjukkan bahwa prevalensi DM di Indonesia untuk usia di atas 15 tahun sebesar 6,9\% dan di Sulawesi Utara sebesar 2,4\%. Pos Pembinaan Terpadu (Posbindu) merupakan pos pelayanan kesehatan untuk masyarakat usia lanjut di suatu wilayah tertentu yang sudah disepakati, yang digerakkan oleh masyarakat. Di Posbindu masyarakat usia lanjut bisa mendapatkan pelayanan kesehatan. Disamping itu, terdapat kegiatan peningkatan kesehatan serta kesejahteraan yang melibatkan peran masyarakat dan organisasi sosial. Kader Posbindu ialah tenaga masyarakat yang telah dilatih, dan dibentuk dalam suatu forum komunikasi alih tehnologi dan pelayanan bimbingan kesehatan masyarakat oleh dan untuk masyarakat yang mempunyai nilai strategis dalam mengembangkan sumber daya manusia sejak dini. Oloeh karena itu, peningkatan pengetahuan kader Posbindu mengenai DM dan hal-hal yang berkaitan perlu dilakukan secara berkesinambungan. Penelitian ini bertujuan untuk mengetahui pengetahuan kader Posbindu mengenai penyakit diabetes melitus (DM). Jenis penelitian ialah kualitatif menggunakan informan. Hasil penelitian mendapatkan bahwa pengetahuan informan sudah baik walaupun masih terdapat hal-hal yang harus lebih ditingkatkan tentang penyakit DM. Simpulan: Para informan sudah mengetahui hal-hal yang harus diperhatikan dalam masyarakat terutama yang berhubungan dengan penyakit DM.
\end{abstract}

Kata kunci: pengetahuan, kader posbindu, diabetes melitus

Menurut American Diabetes Association (2013) sebanyak 25,8 juta anak-anak dan orang dewasa di Amerika Serikat (8,3\% dari populasi) menderita diabetes mellitus (DM). Selain itu didapatkan kondisi pradiabetes sebanyak 79 juta orang dan kasus baru sebanyak 1,9 juta pada orang berusia $\geq 20$ tahun di tahun 2010. Pada mereka yang berusia di bawah 20 tahun, 215.000, atau $0,26 \%$ dari semua orang dalam kelompok usia ini menyandang DM. Sekitar 1 dari setiap 400 anak dan remaja 
menyandang DM. Menurut penelitian yang dilaksanakan di Inggris, lebih dari $80 \%$ pasien berusia $\geq 45$ tahun yang baru didiagnosis menyandang DM setelah 10 tahun diobservasi ternyata berisiko komplikasi penyakit jantung koroner (PJK) $>5 \%$; 73\% (45\% sampai 92\%) hipertensi; dan $73 \%(45-92 \%)$ memiliki konsentrasi kolesterol $>5 \mathrm{mmol} / \mathrm{l}^{1}$

Laporan dari WHO (2013) menunjukkan bahwa penyakit tidak menular sejauh ini merupakan penyebab utama kematian di dunia, yang mewakili $63 \%$ dari semua kematian tahunan. Penyakit ini membunuh lebih dari 36 juta orang setiap tahun.Sekitar $80 \%$ dari semua kematian terjadi di negara berpenghasilan rendah dan menengah. ${ }^{1}$

International Diabetes Federation (IDF) menyebutkan bahwa prevalensi DM di dunia ialah $1,9 \%$ dan telah menjadikan penyakit ini sebagai penyebab kematian urutan ke-7 di dunia, sedangkan pada tahun 2012 angka kejadian DM di dunia sebanyak 371 juta jiwa dengann proporsi kejadian DM tipe 2 (DMT2) 95\% dari populasi dunia yang menderita $\mathrm{DM}^{2}$

Penelitian tentang prevalensi DM pada tahun 2000 Indonesia menempati peringkat ke-4 dengan jumlah pasien DM terbesar di dunia setelah India, Cina dan Amerika Serikat. $^{3}$

Laporan hasil Riset Kesehatan Dasar (Riskesdas) tahun 2013 oleh Departemen Kesehatan menunjukkan bahwa prevalensi DM di Indonesia untuk usia di atas 15 tahun sebesar 6,9\%. Prevalensi DM di Indonesia mengalami peningkatan dari $1,1 \%$ (2007) menjadi 2,1\% (2013). Prevalensi tertinggi DM yang telah didiagnosis oleh dokter terdapat di DI Yogyakarta (2,6\%), DKI Jakarta (2,5\%), Sulawesi Utara $(2,4 \%)$, dan Kalimantan Timur (2,3\%).6 Hal ini menunjukkan bahwa Sulawesi Utara merupakan salah satu provinsi dengan angka prevalensi DM yang tertinggi di Indonesia.,

Telah dibuktikan pula bahwa obesitas menjadi faktor risiko meningkatnya angka kesakitan dan kematian akibat penyakit hipertensi, dislipidemia, DMT2, PJK, stroke, penyakit kandung empedu, osteoartritis, karsinoma endometrium, payudara, usus besar, dan prostat. Keadaan tersebut sesuai dengan hasil Survei Kesehatan Nasional dan Rumah Tangga tahun 1980- 2001 di Indonesia tentang kematian akibat penyakit tidak menular. ${ }^{6}$

Provinsi Sulawesi Utara merupakan salah satu provinsi yang mempunyai prevalensi DM yang cukup tinggi. Menurut Riskesdas (2013), prevalensi DM di Sulawesi Utara pada tahun 2013 berdasarkan jawaban pernah didiagnosis dokter sebesar $2,4 \%$ dan berdasarkan diagnosis atau gejala sebesar 3,6\%. Berdasarkan Profil Kesehatan Sulut (2008), prevalensi DM tertinggi terdapat di Kota Manado yaitu sebesar 1,3\% berdasarkan jawaban pernah didiagnosis dokter dan $2,7 \%$ berdasarkan diagnosis atau gejala. ${ }^{7}$

Pos Pembinaan Terpadu (Posbindu) merupakan pos pelayanan kesehatan untuk masyarakat usia lanjut disuatu wilayah tertentu yang sudah disepakati, yang digerakkan oleh masyarakat dimana mereka bisa mendapatkan pelayanan kesehatan. Posbindu juga merupakan sebuah wadah tempat pelayanan terpadu yang diperuntukkan bagi lansia disuatu daerah tertentu yang didalamnya terdapat pelayanan kesehatan dan kegiatan peningkatan kesehatan serta kesejahteraan yang dalam pelaksanaanya melibatkan peran masyarakat dan organisasi sosial. ${ }^{7}$

Kader Posbindu adalah tenaga masyarakat yang telah dilatih, dan dibentuk dalam suatu forum komunikasi alih tehnologi dan pelayanan bimbingan kesehatan masyarakat oleh dan untuk masyarakat yang mempunyai nilai strategis dalam mengembangkan sumber daya manusia sejak dini. Penelitian ini bertujuan untuk mendapatkan pengetahuan kader Posbindu terhadap penyakit DM.

\section{METODE PENELITIAN}

Jenis penelitian ini ialah kualitatif. $^{8}$ Penelitian dilaksanakan di Kota Manado pada bulan Oktober-Desember 2015. Metode pemilihan sampel menggunakan purposive sampling. Populasi diambil pada 
20 Posbindu di puskesmas Kota Manado yaitu Puskesmas Bahu, Puskesmas Teling, Puskesmas Tikala Baru, Puskesmas Ranomuut, dan di desa-desa yang diatur langsung oleh pemerintah desa dan masyarakat dan di gereja.

Sampel diambil dari kader Posbindu di Kota Manado yang melakukan kegiatan Posbindu secara aktif minimal $1 \mathrm{x} / \mathrm{bulan}$. Dari populasi di atas peneliti melakukan penelitian pada Posbindu yang aktif yaitu Puskesmas Bahu, Puskesmas Tikala Baru, Puskesmas Ranomuut, dan kader posbindu di Gereja Getsemani Paal dua; dari posbindu ini diambil 12 kader posbindu untuk dilakukan penelitian dari peneliti.

Metode pengumpulan data adalah teknik atau cara yang dapat digunakan oleh peneliti untuk mengumpulkan data, serta instrumen pengumpulan data adalah alat bantu yang dipilih dan digunakan oleh peneliti dalam kegiatannya mengumpulkan data agar kegiatan tersebut menjadi sistematis dan lebih mudah. Pengumpulan data merupakan prosedur yang sistematik dan standar untuk memperoleh data yang diperlukan. ${ }^{8,9}$

\section{HASIL PENELITIAN DAN BAHASAN}

Posbindu yang dijadikan tempat penelitian ialah pertama diwilayah Puskesmas Bahu, kedua Puskesmas Tikala Baru, ketiga Puskesmas Ranomuut dan keempat di Gereja Getsemani Paaldua. Dari wilayah kerja Posbindu didapatkan 12 kader Posbindu.

Tabel 1. Karakteristik informan

\begin{tabular}{cclcc}
\hline Informan & $\begin{array}{c}\text { Usia } \\
\text { (tahun) }\end{array}$ & \multicolumn{1}{c}{ Alamat } & $\begin{array}{c}\text { Pendidikan } \\
\text { terakhir }\end{array}$ & Agama \\
\hline $\mathbf{1}$ & 46 & Winangun II lingk.1 & SMA & Kristen Protestan \\
$\mathbf{2}$ & 50 & Winangun II ling.3 & SMA & Kristen Protestan \\
$\mathbf{3}$ & 49 & Tikala ling.2 & SMA & Kristen Protestan \\
$\mathbf{4}$ & 36 & Tikala ling.2 & SMU & Kristen Protestan \\
$\mathbf{5}$ & 30 & Bahu & SMA & Kristen Protestan \\
$\mathbf{6}$ & 40 & Bahu & SMA & Kristen Protestan \\
$\mathbf{7}$ & 39 & Malalayang ling.3 & SMA & Kristen Protestan \\
$\mathbf{8}$ & 46 & Malalayang ling.4 & SMA & Kristen Protestan \\
$\mathbf{9}$ & 44 & Dendengan luar & SMA & Kristen Protestan \\
$\mathbf{1 0}$ & 57 & Paal 2 & SMA & Kristen Protestan \\
$\mathbf{1 1}$ & 52 & Paal 2 & SMU & Kristen Protestan \\
$\mathbf{1 2}$ & 39 & Tingkulu Teling & SMA & Kristen Protestan \\
\hline
\end{tabular}

Semua informan mengatakan penyakit DM bisa juga disebut dengan istilah kencing manis. Hal ini bisa dilihat dari pernyataan Informan I-XII menyatakan "iya"..... dan jawaban ini menunjukkan langsung bahwa informan menyatakan DM adalah penyakit yang sering dikenal dengan istilah kencing manis.

Penyakit DM dikenal oleh masyarakat dengan istilah kencing manis dan DM merupakan kelebihan kadar gula dalam darah serta penyakit turunan. Hal ini bisa dilihat dari pernyataan Informan IV "Penyakit DM itu adalah kelebihan gula dan disebut juga kencing dan juga penyakit turunan" dan pernyataan Informan X "Penyakit kencing manis dan kelebihan gula dalam darah". Dan rata-rata dari informan yang lain menyatakan hamper seperti informan I dan X.

Terdapat beberapa faktor yang menyebabkan penyakit DM antara lain, gaya hidup, kurang berolahraga, makanan yang manis, makan tidak teratur dan faktor keturunan. Hal ini bisa dilihat dari pernyataan Informan VII "Menurut saya gaya hidup, keturunan, dan berat badan yang berlebih"dan Pernyataan Informan 
XII "Menurut saya makan tidak teratur dan jarang berolah-raga"

Dari para informan menyatakan penyakit DM dapat diturunkan kepada anaknya atau keturunannya, tetapi ada juga yang menyatakan tidak juga. Seperti pernyataan Informan III "Bisa yah, karena satu darah. Dan bisa juga tidak karena anaknya atau keturunannya bisa mengatur pola makan" dan Pernyataan Informan IV "karena kalau anaknya memiliki pola hidup yang baik tidak akan terkena. Jadi menurut saya tergantung"

Menurut para informan gejala-gejala dari penyakit DM ialah mudah lelah, sering buang air kecil pada malam hari, sering capek, dan berat badan menurun. Seperti pada pernyataan Informan II "Sering kencing malam, berat badan menurun", Informan VIII "Mudah lelah dan sering buang air kecil pada malam hari" dan pernyataan Informan XII "Menurut saya berat badan menurun, sering buang air kecil dan mudah lelah"

Cara-cara yang dilakukan oleh seseorang untuk menghindari dan mencegah penyakit DM ialah harus sering berolahraga, makan teratur, dan mengurangi makanan yang banyak mengandung gula dan jangan banyak makan nasi. Pernyataan Informan II "Menurut saya jangan makan yang manismanis dan sering olahraga", Informan IX "Hindari minum gula dan nasi"

Para informan menyatakan bahwa pengobatan DM ialah insulin, dan harus langsung ke rumah sakit atau ke dokter dan juga boleh digunakan obat tradisional apabila dengan anjuran dokter. Dari pernyataan Informan XI "Menurut saya pengobatan DM ialah insulin dan boleh juga pakai obat tradisional yang disarankan oleh dokter", dan Informan XII "Menurut saya langsung ke rumah sakit atau dokter untuk mendapatkan pengobatan dan jangan minum obat tradisional sembarangan"

Salah satu komplikasi dari penyakit DM ialah infeksi pada kaki yang lambat sembuh. Penyakit DM bisa menyebabkan komplikasi penyakit lain seperti ginjal.
Dari pernyataan Informan I "Menurut saya iyah, karena ini merupakan akibat dari DM yang sudah lama tidak sembuh", Informan V"Bisa jadi, karena apa bila sudah tidak bisa ditangani akan terjadi komplikasi" dan pernyataan Informan $\mathbf{X}$ "Luka yang lambat sembuh dan infeksi merupakan akibat dari DM"

Makanan yang harus dihindari oleh orang yang menderita penyakit DM ialah semua makanan yang mengandung manis contohnya nasi dan gula. Seperti pada pernyataan pada Informan IV "Makanan yang tidak boleh dimakan ialah yang mengandung gula, sirup dan yang lain bukan tidak boleh dimakan tetapi dikurangi" dan pernyataan Informan XII "Menurut saya minuman yang mengandung gula atau manis seperti sirup"

Dari pernyataan informan diatas mereka menyatakan penyakit DM bisa disembuhkan bila tidak dengan komplikasi yang berbahaya. Dan apabila sembuh tidak akan kembali seperti semula atau $100 \%$. Seperti pernyataan Informan III "Bisa disembuhkan tapi tidak seperti sebelumnya atau tidak $100 \%$ karena apabila sudah terkena komplikasi lamah untuk sembuh", dan pernyataan Informan XII "Bisa sembuh tapi harus ditunjang dengan obat, dan itupun komplikasinya tidak berat.

\section{SIMPULAN}

Dari hasil penelitian dan bahasan dapat disimpulkan bahwa pengetahuan informan sudah sangat baik sekalipun ada hal-hal yang harus lebih ditingkatkan tentang apa yang mereka pahami tentang penyakit diabetes melitus, faktor-faktor penyebab, gejala, cara menghindari dan mencegah, pengobatan, dan komplikasi tentang diabetes melitus.

Para informan sudah mengetahui halhal yang harus diperhatikan dalam masyarakat terutama yang berhubungan dengan penyakit diabetes melitus sehingga para kader Posbindu menjadi perpanjangan tangan dari petugas kesehatan untuk menyatakan kesehatan itu penting. 


\section{SARAN}

Kader Posbindu diharapkan lebih giat dan terus belajar tentang penyakit diabetes mellitus, bahkan semua penyakit yang berhubungan dimasyarakat.

Kader Posbindu terlebih dahulu mampu mengatur pola hidup sebelum turun ke masyarakat agar ketika sudah di masyarakat, masyarakat akan mengikuti cara hidup dari setiap kader posbindu.

Sebaiknya semua Posbindu menambah wawasan seperti melakukan penyuluhan pada semua kader Posbindu dan masyarakat.

Pemerintah dan pihak kesehatan harus bekerja sama untuk membuat kader Posbindu lebih baik untuk kepentingan masyarakat.

Peneliti selanjutnya mengenai tingkat pengetahuan kader Posbindu terhadap diabetes melitus diharapkan mampu mengembangkan penelitian ini dengan dengan lebih baik dan memperdalam menggali informasi yang lebih baik, memperbaiki dan melengkapi metode penelitian sebelumnya agar didapatkan hasil penelitian yang lebih baik.

\section{DAFTAR PUSTAKA}

1. Harding AH, Day NE, Khaw KT, Bingham S, Luben R, Welsh A, et al. Dietary fat and the risk of clinical type diabetes: The European prospective investigation of cancer -
Norfolk study. Am J Epidemiol. 2004;159(1);73-82.

2. Palestine B. 2007. Pendidikan kesehatan dalam pengelolaan diabetes secara mandiri (diabetes self-management education) bagi diabetes dewasa (online). Available from: http://www.bondanpalestin.com

3. Sargowo D, Andarini S. Pengaruh komposisi asupan makan terhadap komponen sindrom metabolik pada remaja. Jurnal Kardiologi Indonesia. 2011;32:16.

4. Riset Kesehatan Dasar 2013. Laporan RISKESDAS. Badan Penelitian dan Pengembangan Kesehatan Departemen Kesehatan, Republik Indonesia.

5. Lawrence JM, Bennett P, Young A, Robinson AM. 2001. Screening for diabetes in general practice: cross sectional population study. BMJ. 2001;323(7312):548-51.

6. Soewondo. Hidup Sehat Bebas Diabetes. Yogyakarta: Araska, 2006.

7. Departemen Kesehatan Republik Indonesia 2006. Badan Penelitian dan Pengembangan Kesehatan Departemen Kesehatan RI.

8. Maleong LJ. Metodologi Penelitian Kualitatif. Bandung: Remaja Rosdakarya Offset, 2008; p. 4-5.

9. Tanzeh A. Metode Penelitian Praktis. Jakarta Pusat: PT Bina Ilmu, 2004; p. 28. 